\title{
A Pythagorean Cubic Fuzzy Methodology Based on TOPSIS and TODIM Methods and its Application to Software Selection Problem
}

Sukran Seker ( $\square$ sseker@yildiz.edu.tr)

Yildiz Teknik Universitesi https://orcid.org/0000-0002-8726-6148

Cengiz Kahraman

Istanbul Teknik Universitesi

\section{Research Article}

Keywords: TODIM, TOPSIS, Pythagorean cubic fuzzy sets, software selection, MCDM

Posted Date: July 27th, 2021

DOl: https://doi.org/10.21203/rs.3.rs-709398/v1

License: (c) (1) This work is licensed under a Creative Commons Attribution 4.0 International License.

Read Full License

Version of Record: A version of this preprint was published at Soft Computing on November 8th, 2021. See the published version at https://doi.org/10.1007/s00500-021-06469-8. 


\title{
A Pythagorean cubic fuzzy Methodology Based on TOPSIS and TODIM methods and its application to software selection problem
}

\author{
Sukran Seker ${ }^{1} \quad$ Cengiz Kahraman ${ }^{2}$ \\ ${ }^{1}$ Yildiz Technical University, Industrial Engineering Department, 34349, Yildiz, Istanbul, Turkey \\ ${ }^{2}$ Istanbul Technical University, Industrial Engineering Department, 34367, Macka, Istanbul, Turkey
}

\begin{abstract}
Software selection process for many organizations is a challenging task to conduct their business activities and sustain competitiveness. This paper develops a new hybrid multi-criteria decision making (MCDM) method to select the most effiecient vendor-supplied software package which is used in all business activities for planning or designing, organizing, and supervising functions by operations management of a fuel oil company operated in Turkey. The proposed method is a hybridization of two well-known MCDM approaches, namely TODIM (an acronym in Portuguese for Interactive and Multi criteria Decision Making) and TOPSIS (technique for order preference by similarity to an ideal solution) using Pythagorean cubic fuzzy sets (PCFS) to manage uncertainty, subjectivity and bias of decision makers (DMs). To prove the efficiency and applicability of the proposed method, a real life application to select best software package for fuel oil company, is conducted. Finally, a sensitivity and comparison analyses are carried out to verify validity and stability of the results obtained by the proposed approach.
\end{abstract}

Keywords: TODIM, TOPSIS, Pythagorean cubic fuzzy sets, software selection, MCDM.

${ }^{1}$ Corresponding Author. E-mail: sseker@yildiz.edu.tr 


\section{Introduction}

Selecting a software system and its vendor are critical parts of any organization since the selected software runs essential and critical business functions to manage operations such as production planning, quality control, inventory management, sales and marketing in the organization. Excellent software doesn't only meet the requirements of organizations but also support higher corporate goals and strategies to sustain competitive advantage (Rao and Rajesh 2009). Thus, the selection and implementation of such software is known as a complex and strategic decision for many companies since it requires many critical factors to be considered (Cisneros et al. 2017).

Although several software selection methods are applied by the modern professional establishments, Multi-Criteria Decision Making (MCDM) methods are preferred for many cases since the decision makers (DMs) face with numerous and conflicting criteria during evaluation process (Cakır 2016). MCDM methods have been applied to obtain more reasonable decisions in many fields. Considering the importance of appropriate software selection for organizations, the subject has received much more attention from both researchers and practitioners in the literature (Sarkis and Talluri 2004; Rao and Rajesh 2009; Victor and Upadhyay 2011; Kazancoglu and Burmaoglu 2013; Eastham et al. 2014; Yazgan et al. 2009; Bijoyeta and Misra 2018; Karsak and Ozogul 2009; Mulebeke and Zheng 2006).

However, due to uncertain, incomplete and complex subjective knowledge of the DMs', fuzzy sets (FSs) introduced by Zadeh (1965) have taken much consideration by researchers during decision making processes. In recent years, as the extensions of ordinary FSs, the intuitionistic fuzzy sets (IFS) introduced by Atanassov $(1986,1995)$ and interval-valued intuitionistic fuzzy sets (IVIFS) developed by (Atanassov and Gargov 1989) were presented. Membership and a non-membership degree to every element are assigned in the IFS and IVIFS with the aim of better definition of imprecise and vague information in real life applications. Then, Pythagorean fuzzy sets (PFSs) were developed by Yager and Abbasov in 2013. PFSs provides to reflect DMs opinions in a larger domain than IFSs and IVIFSs. Accordingly, PFS satisfy the condition that the squared sum of membership and non-membership degrees is equal to or less than 1 . However, in some practical MCDM problems, PFSs can be inadequate since the membership and non-membership degrees of PFSs are defined by a single numerical value. To handle this problem, Peng and Yang (2016) presented the version of interval valued Pythagorean fuzzy sets (IVPFSs) as the extension of PFSs. 
From the existing literature, many scholars have carried out various types of fuzzy set extensions, e.g.,IFS, IVIFS, PFS and IVPFSs. (Zhang et al. 2016; Hajiagha et al. 2013; Nguyen 2017; Nirmala and Uthra 2016; Wang et al. 2011; Wu et al. 2013; Zhang and Xu 2014; Garg 2017; Ilbahar et al. 2018; Rahman et al. 2019; Biswas and Sarkar 2019; Ilbahar and Kahraman 2018).

Since PFSs and IVPFSs are more effective to cope with incomplete and vague information in decision making problems, Khan et al. (2019 a, b) proposed the concept of Pythagorean cubic fuzzy sets (PCFS) as the generalization of IVPFSs considering the confidence level of the attributes. In PCFS the membership degree is an IVPFS and non-membership degree is PFS. Thus, the motivation of PCFS has more capability to deal with vague and imprecise information derive from subjectivity of DMs in complex decision-making problems by incorporating IVPFS and PFS simultaneously (Abbas et al. 2019). There is only a limited number of studies dealing with PCFS in the literature since it is a new extension. Khan et al. (2019 a) introduced Pythagorean cubic fuzzy (PCF) weighted and geometric operators along with their order. Talukdar and Dutta (2019) presented a family of distance measures for PCFSs and applied it in medical decision-making problem. Khan et al. (2020) combined PCF with TOPSIS method under incomplete weight information. Hussain et al. (2021) presented some novel Pythagorean cubic fuzzy Einstein weighted geometric (PCFEWG) operators to solve multiple attribute group decision-making problems. Xu et al. (2021) suggested Cubic linguistic Pythagorean fuzzy sets based power Hamy mean operator, the cubic linguistic Pythagorean fuzzy power average operator and their weighted forms. Fahmi et al. (2021) proposed the score and accuracy function of the cubic Pythagorean linguistic fuzzy numbers with some aggregation operators such as CPLFAA, CGPLFAA, CPLFGA, CPLFMSM, and CPLFWMSM etc.

In this study, two well-known MCDM methods (TODIM and TOPSIS) are integrated and presented as a new extended hybrid MCDM method using PCF numbers (PCFNs) to solve complex decision making problems. The implementation process of the new hybrid MCDM method with PCFS isn't difficult due to easy adaptable of PCFS to the new hybrid method. To the best of the authors' knowledge, this hybrid method is introduced as the first time in the literature. The TODIM method is inspired by the prospect theory considering the DMs' psychological behavior. TODIM is applied to handle situations where the DMs' bounded rationality is taken into consideration. TODIM method is used in this study since it can better describe the bounded rational behavior of decision makers. However, since the distances play important role in the ranking of the alternatives in MCDM problems, TOPSIS is applied in the 
ranking of alternatives since it utilized Euclidean distances to measure the alternatives with their positive ideal solution (PIS) and negative ideal solution (NIS). The model is constructed based on PCF to describe fuzzy and imprecise information more comprehensively and handle the uncertain problems as an effective tool in uncertain environment by incorporating IVPFS and PFS simultaneously

Thus, the proposed hybrid method not only handles the uncertainty in real decision making problems, but also considers the DMs' psychological behavior in the confront of risk in the selection process. The second contribution of this study is to analyze the behavior of the TODIM and TOPSIS as MCDM methods when they are hybridized. Thirdly, subjective dimension, human opinions with uncertainties are satisfied strongly by using PCF for complex and challenging problems we face in real world applications. Thus, the applicability and efficiency of the proposed approach is verified by choosing appropriate vendor-supplied software package which is utilized to conduct the critical processes of the Turkish fuel oil company.

The rest of this paper is constructed as follows: Literature Review is given in Section 2. Some preliminaries are presented in Section 3. The proposed approach is given in Section 4. In order to represent applicability of the proposed approach a case study for vendor-supplied software selection is introduced in Section 5. Sensitivity analysis is performed to confirm the validity of the proposed approach. In order to prove the feasibility and effectiveness of the developed method, a comparative analysis is conducted between the proposed approach and existing methods. Conclusion section with future suggestions is introduced in the last section.

\section{Literature Review}

As well-known MCDM methods, TODIM and TOPSIS are used with different fuzzy extensions in the literature. For example, Lourenzutti and Krohling (2013) introduced TODIM under intuitionistic fuzzy and random environment. The method used Bayesian theorem to obtain the ranking of the alternatives. Krohling and Pacheco (2014) carried out TODIM method to cope with MCDM problems under uncertain environment using IVIFSs. Li et al. (2015) applied TODIM method with IVIFSs. In the presented method, the entropy method was used for determination of the weights. Ren et al. (2016) proposed the TODIM approach by applying PFS to solve MCDM problems. Biswas and Sarkar (2019) presented IVPF-TODIM method by introducing some new point operator-based similarity procedures. Ji et al. (2016) presented a projection-based TODIM method for multi-valued neutrosophic fuzzy information and applied it to obtain the best personnel. Wei (2018) extended the TODIM model with the picture fuzzy 
numbers (PFNs). Huang et al. (2018) presented IVPF-TODIM method by applying ordinary TODIM method. Peng and Dai (2017) presented Pythagorean fuzzy stochastic MCDM method considering prospect theory and regret theory. Xu and Zhang (2013) presented a novel method by applying TOPSIS method taking into account hesitant fuzzy sets and an application of this new method was conducted to decide most desirable energy policy. Chen (2015) proposed IVIF-TOPSIS method using an inclusion comparison method to handle MCGDM problems. Zhou and Chen (2019) proposed PF-TOPSIS method by developing a novel distance approach. The proposed distance approach was used to compute the distances from the PIS and the NIS. Lin et al. (2018) applied PF-TOPSIS method based on correlation-based closeness indices to reveal the ranking orders.

Many hybrid approaches based on MCDM methods are presented in the literature for different research fields. For example, Ozkaya and Erdin (2020) proposed Analytical Network Process (ANP) and TOPSIS methods to determine the smarter and more sustainable city around the World. Tokyo and London were at the forefront of smart cities as a result of the study. Beheshtinia and Omidi (2017) introduced integrated MCDM methods for performance evaluation of banks based on criteria determined by balanced scorecard (BSC) methodology and corporate social responsibility (CSR) views. Accordingly, the weights of criteria were determined using Analytic Hierarchy Process (AHP) and modified digital logic (MDL), alternative rankings were obtained using fuzzy TOPSIS (FTOPSIS) and Fuzzy Vlse Kriterijumska Optimizacija I Kompromisno Resenje (VIKOR) methods. Choquet integral was used to cope with interacting criteria in the aggregation step. Lo et al. (2020) presented an integrated risk assessment model using the decision-making trial and evaluation laboratory (DEMATEL) technique and TOPSIS method to determine the ranking of the failure modes for machine tool manufacturing company. Bakioglu and Atahan (2021) suggested a new hybrid MCDM methods based on the AHP, the TOPSIS and VIKOR methods under Pythagorean fuzzy environment for decision making in self-driving vehicles. Bera et al. (2019) proposed a hybrid approach based on TOPSIS and multi-objective optimization on the basis of ratio analysis (MOORA) methods in interval type-2 fuzzy (IT2F) environment for supplier selection. Li et al. (2021) presented a MCDM model including IVIF DANP and TODIM methods to evaluate the he quality community question-answering (CQA) websites. Aydoğan and Özmen (2020) introduced a hybrid MCDM method, consists of rough the stepwise weight assessment ratio analysis (SWARA) and TODIM (an acronym in Portuguese of interactive and multi-criteria decision making) to evaluate the global competitiveness of the Travel \& Tourism (T\&T) sector. 
Liang et al. (2019) integrated VIKOR and TODIM methods taking into account Pythagorean fuzzy entropy and cross-entropy measures.

In this study two well-known methods are integrated under PCF environment. In the literature, many hybrid TODIM-TOPSIS methods were successfully introduced. Khamseh and Mahmoodi (2014) introduced Fuzzy TOPSIS and TODIM methods to select green supplier. Fuzzy TOPSIS was used as input for TODIM method in determining the weights. The proposed method was applied in car industries of Iran. Lourenzutti et al. (2017) proposed Group Modular Choquet Random (GMC-RTOPSIS) and Group Modular Choquet Random (GMCRTODIM) for group decision making considering random or deterministic factors. Choquet integral was used to cope with interacting criteria in the aggregation step. Krohling et al. (2019) presented Z-TODIM and Z-TOPSIS as a direct extension of the fuzzy TODIM and fuzzy TOPSIS, respectively. The proposed methods were applied in two case studies. The proposed approach was compared with crisp version of methods to verify the approach. The results produced feasible results. Lourenzutti and Krohling (2014) modified TOPSIS and TODIM methods using Hellinger distance to handle information defined as probability distributions. They used the stochastic dominance to determine which alternative was more appropriate considering any criterion. Liu et al. (2020) presented the TOPSIS method and TODIM method based on linguistic picture fuzzy sets (LPFS). Once the linguistic picture fuzzy weighted average and linguistic picture fuzzy weighted geometric operators were developed, they introduced TODIM and TOPSIS methods under linguistic picture fuzzy environment.

Combining the strengths of TODIM and TOPSIS under PCF makes the proposed method a useful and comprehensive tool in handling the uncertainty involves in the decision-making process. As a distance based method, TOPSIS is successfully and frequently used for MCDM problems. TOPSIS is chosen in the current study since it has mathematical simplicity, rationality and flexibility in the definition of the alternative set and solve large and complex decision-making problems efficiently (Kim et al 1997; Zanakis et al. 1998). The TOPSIS method is also different from other decision making models due to it allows the replacement of unnecessary parameters with the parameters necessary for decision making problems. (Khan et al. 2020).

As a result, in order to obtain compromised solution in MCDM problems, we adapt the TOPSIS method to TODIM under PCF environment to cope with fuzzy and imprecise information together with considering DM's psychological behavior. 


\section{Preliminaries}

PFSs and IVPFSs are important tools to cope with fuzziness and ambiguity during decision making. As an extension of PFSs and IVPFSs, the PCFSs concept was introduced by Khan et al. (2019 a). PCFSs have the membership and non-membership degrees identified by cubic fuzzy numbers. PCF must satisfy the conditions that the squared sum of its membership and non-membership degree is less than or equal to $\langle\tilde{1}, 1\rangle$ (Khan et al. 2020). Some preliminaries on PCFSs are as follows:

Definition 1 (Khan et al. 2019 a). PCF set $\left(C_{p}\right)$ is expressed by a set of ordered pairs as membership and non-membership over a fixed universal set $X$ as follows:

$A_{P C}=\left\{\left(\left(x, \gamma A_{P C}(x), \tau A_{P C}(x)\right) \mid x \in X\right)\right\}$,

in which $\gamma A_{P C}(x)=\left\langle A_{P C}(x), \lambda_{P C}(x)\right\rangle$ and $\tau A_{P C}(x)=\left\langle\tilde{A}_{P C}(x), \mu_{P C}(x)\right\rangle$ shows the membership and non-membership degree under the condition that

$0 \leq\left(\sup \left(A_{P C}(x)\right)\right)^{2}+\sup \left(\tilde{A}_{P C}(x)\right)^{2} \leq 1,0 \leq \lambda^{2}{ }_{P C}(X)+\mu^{2}{ }_{P C}(X) \leq 1$

However, the value of indeterminacy for PCFSs can be illustrated as:

$\pi_{A_{P C}}=\left\langle\sqrt{1-\left(\sup \left(A_{P C}(x)\right)\right)^{2}-\left(\sup \left(\tilde{A}_{P C}(x)\right)\right)^{2}}, \sqrt{1-\lambda^{2}{ }_{P C}(x)-\mu^{2}{ }_{P C}(x)}\right\rangle$

Definition 2 (Khan et al. 2019 a). Let $A_{C 1}=\left(\left\langle A_{1}, \lambda_{1}\right\rangle,\left\langle\tilde{A}_{1}, \mu_{1}\right\rangle\right)$ and $A_{C 2}=$ $\left(\left\langle A_{2}, \lambda_{2}\right\rangle,\left\langle\tilde{A}_{2}, \mu_{2}\right\rangle\right)$ are two PCFNs and $\delta>0$ where $A_{1}=\left[a_{1}, b_{1}\right], \tilde{A}_{1}=\left[\tilde{a}_{1}, \tilde{b}_{1}\right], A_{2}=$ $\left[a_{2}, b_{2}\right], \tilde{A}_{2}=\left[\tilde{a}_{2}, \tilde{b}_{2}\right]$ the arithmetic operations between $A_{C 1}$ and $A_{C 2}$ are as follows:

$$
\begin{aligned}
& A_{C 1} \oplus A_{C 2} \\
& =\left\langle\left[\sqrt{\left(a_{1}\right)^{2}+\left(a_{2}\right)^{2}-\left(a_{1}\right)^{2}\left(a_{2}\right)^{2}}, \sqrt{\left(b_{1}\right)^{2}+\left(b_{2}\right)^{2}-\left(b_{1}\right)^{2}\left(b_{2}\right)^{2}}\right] ; \sqrt{\lambda_{1}{ }^{2}+\lambda_{2}{ }^{2}-\lambda_{1}{ }^{2} \lambda_{2}{ }^{2}}\right\rangle \\
& \left\langle\left[\tilde{a}_{1} \tilde{a}_{2}, \tilde{b}_{1} \tilde{b}_{2}\right] ;\left[\mu_{1} \mu_{2}\right]\right\rangle \\
& A_{C 1} \otimes A_{C 2}=\left\langle\left[a_{1} a_{2}, b_{1} b_{2}\right] ; \lambda_{1} \lambda_{2}\right\rangle, \\
& \left\langle\left[\sqrt{\left(\tilde{a}_{1}\right)^{2}+\left(\tilde{a}_{2}\right)^{2}-\left(\tilde{a}_{1}\right)^{2}\left(\tilde{a}_{2}\right)^{2}}, \sqrt{\left(\tilde{b}_{1}\right)^{2}+\left(\tilde{b}_{2}\right)^{2}-\left(\left(\tilde{b}_{1}\right)^{2}\left(\tilde{b}_{2}\right)^{2}\right.}\right] ; \sqrt{\mu_{1}{ }^{2}+\mu_{2}{ }^{2}-\mu_{1}{ }^{2} \mu_{2}{ }^{2}}\right\rangle
\end{aligned}
$$

$\delta A_{C 1}$

$=\left\langle\left[\sqrt{1-\left(1-\left(a_{1}\right)^{2}\right)^{\delta}}, \sqrt{1-\left(1-\left(b_{1}\right)^{2}\right)^{\delta}}\right] ; \sqrt{1-\left(1-\lambda_{1}{ }^{2}\right)^{\delta}}\right\rangle,\left\langle\left[\left(\tilde{a}_{1} \tilde{a}_{2}\right)^{\delta},\left(\tilde{b}_{1} \tilde{b}_{2}\right)^{\delta}\right]\right\rangle ;$ $\left(\mu_{1} \mu_{1}\right)^{\delta}$ 


$$
\begin{aligned}
& A_{C 1}{ }^{\delta}=\left\langle\left[\left(a_{1} a_{2}\right)^{\delta},\left(b_{1} b_{2}\right)^{\delta}\right] ;\left(\lambda_{1} \lambda_{2}\right)^{\delta}\right\rangle,\left\langle\left[\sqrt{1-\left(1-\left(\tilde{a}_{1}\right)^{2}\right)^{\delta}}, \sqrt{1-\left(1-\left(\tilde{b}_{1}\right)^{2}\right)^{\delta}}\right]\right\rangle \\
& \left(\sqrt{1-\left(1-\mu_{1}^{2}\right)^{\delta}}\right)
\end{aligned}
$$

Definition 3 (Khan et al. 2019 b). Pythagorean Cubic Fuzzy Weighted Average (PCFWA): Let $A_{C i}=\left(\left\langle A_{i} ; \lambda_{i}\right\rangle,\left\langle\tilde{A}_{i} ; \mu_{i}\right\rangle\right) \quad(\mathrm{i}=1,2, \ldots, \mathrm{n})$ be a collection of all PCFNs and $\mathrm{w}=$ $\left(w_{1}, w_{2}, \ldots \ldots, w_{n}\right)^{T}$ be the weight vector of $p_{c i}=(\mathrm{i}=1,2, \ldots, \mathrm{n})$ with $w_{i} \geq 0$ where $w_{i} \in[0,1]$ and $\sum_{i=1}^{n} w_{i}=1$. The aggregation of PCFNs using PCFWA operator is

$$
\begin{aligned}
& \operatorname{PCFWA}\left(A_{C 1}, A_{C 2} \ldots \ldots, A_{C n}\right)= \\
& =\left\langle\left[\sqrt{1-\prod_{i=1}^{n}\left(1-a_{i}^{2}\right)^{w i}}, \sqrt{1-\prod_{i=1}^{n}\left(1-b_{i}^{2}\right)^{w i}} ; \sqrt{\left.1-\prod_{i=1}^{n}\left(1-\lambda_{i}^{2}\right)^{w i}\right\rangle},\right.\right. \\
& \left\langle\left[\prod_{i=1}^{n} \tilde{a}_{i}^{w i}, \prod_{i=1}^{n} \tilde{b}_{i}^{w i}\right] ; \prod_{i=1}^{n} \tilde{\mu}_{i}^{w i}\right\rangle
\end{aligned}
$$

Definition 4 (Khan et al. 2019 b). Pythagorean Cubic Fuzzy Weighted Geometric (PCFWG) average operator: Let $A_{C i}=\left(\left\langle A_{i} ; \lambda_{i}\right\rangle,\left\langle\tilde{A}_{i} ; \mu_{i}\right\rangle\right)(\mathrm{i}=1,2, \ldots, \mathrm{n})$ be a set of all PCFNs and $\mathrm{w}=\left(w_{1}, w_{2}, \ldots ., w_{n}\right)^{T}$ be the weight vector of $p_{c i}=(\mathrm{i}=1,2, \ldots, \mathrm{n})$ with $w_{1} \geq 0$ where $w_{i} \in$ $[0,1]$ and $\sum_{i=1}^{n} w_{i}=1$. The aggregation of PCFNs by applying PCFWG operator is $\operatorname{PCFWG}\left(A_{C 1}, A_{C 2} \ldots \ldots, A_{C n}\right)=$

$$
\begin{aligned}
& =\left(\left\langle\left[\prod_{i=1}^{n}\left(a_{i}\right)^{w i}, \prod_{i=1}^{n}\left(b_{i}\right)^{w i}\right] ; \prod_{i=1}^{n}\left(\lambda_{i}\right)^{w i}\right\rangle,\left\langle\sqrt{\left[1-\prod_{i=1}^{n}\left(1-\tilde{a}_{i}^{2}\right)^{w i}\right]},\left(1-\prod_{i=1}^{n}(1-\right.\right.\right. \\
& \left.\left.\left.\left.\tilde{b}_{i}^{2}\right)^{w i}\right)\right\rangle\right) ; \sqrt{\left(1-\prod_{i=1}^{n}\left(\mu_{i}^{2}\right)^{w i}\right)}
\end{aligned}
$$

Definition 5 (Khan et al. 2019 a). Let $A_{C 1}=\left(\left\langle A_{1} ; \lambda_{1}\right\rangle,\left\langle\tilde{A}_{1} ; \mu_{1}\right\rangle\right)$ and $A_{C 2}=\left(\left\langle A_{2} ; \lambda_{2}\right\rangle,\left\langle\tilde{A}_{2} ; \mu_{2}\right\rangle\right)$ are two PCFNs where $A_{C 1}=\left[a_{1}, b_{1}\right], \widetilde{A_{C 1}}=\left[\tilde{a}_{1}, \tilde{b}_{1}\right], A_{C 2}=\left[a_{2}, b_{2}\right], \widetilde{A_{C 2}}=\left[\tilde{a}_{2}, \tilde{b}_{2}\right]$. The distance between two PCFNs is identified as:

$$
\begin{aligned}
& d\left(A_{C 1}, A_{C 2}\right)=\frac{1}{6}\left[\left|a_{1}^{2}-a_{2}^{2}\right|+\left|b_{1}^{2}-b_{2}^{2}\right|+\left|\tilde{a}_{1}^{2}-\tilde{a}_{2}^{2}\right|+\left|\tilde{b}_{1}^{2}-\tilde{b}_{2}^{2}\right|+\left|\lambda_{1}^{2}-\lambda_{2}^{2}\right|+\right. \\
& \left.\left|\mu_{1}^{2}-\mu_{2}^{2}\right|\right]
\end{aligned}
$$

Definition 6 (Khan et al. 2019 b). Let $A_{C}=(\langle A ; \lambda\rangle,\langle\tilde{A} ; \mu\rangle)$ be a PCFN where $A=(a, b), \tilde{A}=$ $(\tilde{a}, \tilde{b})$, the score value of $A_{C}$ is expressed as:

$$
S\left(A_{C}\right)=\left(\frac{a+b-\lambda}{3}\right)^{2}-\left(\frac{\tilde{a}+\tilde{b}-\lambda}{3}\right)^{2} \text { where } S\left(A_{C}\right) \in[-1,1]
$$


Definition 7 (Khan et al. 2019 b). Let $A_{C 1}=\left(\left\langle A_{1}, \lambda_{1}\right\rangle,\left\langle\tilde{A}_{1}, \mu_{1}\right\rangle\right)$ and $A_{C 2}=$ $\left(\left\langle A_{2}, \lambda_{2}\right\rangle,\left\langle\tilde{A}_{2}, \mu_{2}\right\rangle\right)$ are two PCFNs

$A_{1}=\left[a_{1}, b_{1}\right], \tilde{A}_{1}=\left[\tilde{a}_{1}, \tilde{b}_{1}\right], A_{2}=\left[a_{2}, b_{2}\right], \tilde{A}_{2}=\left[\tilde{a}_{2}, \tilde{b}_{2}\right]$ the score function be $\mathrm{s}\left(A_{C 1}\right)$ and $\mathrm{s}\left(A_{C 2}\right)$.

If $s\left(A_{C 1}\right)<\mathrm{s}\left(A_{C 2}\right)$, then $A_{C 1}<A_{C 2}$

If $s\left(A_{C 1}\right)>\mathrm{s}\left(A_{C 2}\right)$, then $A_{C 1}>A_{C 2}$

If $s\left(A_{C 1}\right)=\mathrm{s}\left(A_{C 2}\right)$, then $A_{C 1} \sim A_{C 2}$

Definition 8 (Khan et al. 2019 b). Let $A_{C}=(\langle A, \lambda\rangle,\langle\tilde{A}, \mu\rangle)$ be a PCFN where $A=(a, b), \tilde{A}=$ $(\tilde{a}, \tilde{b})$, the accuracy value of $A_{C}$ is expressed as:

$\propto\left(A_{C}\right)=\left(\frac{a+b-\lambda}{3}\right)^{2}+\left(\frac{\tilde{a}+\tilde{b}-\lambda}{3}\right)^{2}$ where $\propto\left(A_{C}\right) \in[0,1]$

Definiton 9 (Khan et al. 2019 b). Let $A_{C 1}=\left(\left\langle A_{1}, \lambda_{1}\right\rangle,\left\langle\tilde{A}_{1}, \mu_{1}\right\rangle\right)$ and $A_{C 2}=$

$\left(\left\langle A_{2}, \lambda_{2}\right\rangle,\left\langle\tilde{A}_{2}, \mu_{2}\right\rangle\right)$ are two PCFNs $A_{1}=\left[a_{1}, b_{1}\right], \tilde{A}_{1}=\left[\tilde{a}_{1}, \tilde{b}_{1}\right], A_{2}=\left[a_{2}, b_{2}\right], \tilde{A}_{2}=\left[\tilde{a}_{2}, \tilde{b}_{2}\right]$

the aacuracy function be $\propto\left(A_{C 1}\right)$ and $\propto\left(A_{C 2}\right)$.

If $\propto\left(A_{C 1}\right)<\propto\left(A_{C 2}\right)$, then $A_{C 1}<A_{C 2}$

If $\propto\left(A_{C 1}\right)>\propto\left(A_{C 2}\right)$, then $A_{C 1}>A_{C 2}$

If $\propto\left(A_{C 1}\right)=\propto\left(A_{C 2}\right)$, then $A_{C 1} \sim A_{C 2}$

\subsection{TOPSIS Method}

TOPSIS was introduced in 1981 by Yoon and Hwang. The optimal decision point is determined as shortest distance from the PIS and the longest distance from the NIS.

Step 1: Create a decision matrix (A). The decision matrix is built by the DM. The decision matrix can be represented as follows:

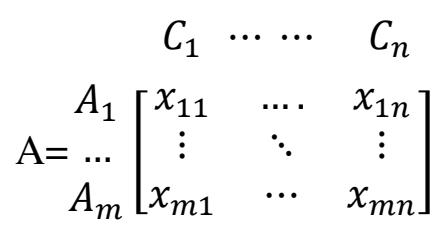

where $\mathrm{m}$ shows the alternatives, $\mathrm{n}$ shows the criteria.

Step 2: Establish normalized decision matrix $(\mathrm{R})$. The normalized matrix is built using the Equation (13).

$r_{i j}=\frac{x_{i j}}{\sqrt{\sum_{i=1}^{m} x_{i j}^{2}}} \quad i=1,2, \ldots, \mathrm{m} ; j=1,2, \ldots, \mathrm{n}$ 
The normalized matrix is shown as follows:

$$
R_{i j}=\left[\begin{array}{cccc}
r_{11} & r_{12} & \ldots & r_{1 n} \\
r_{21} & r_{22} & \ldots & r_{2 n} \\
\cdot & & & \cdot \\
\cdot & & & \cdot \\
\cdot & & & \cdot \\
r_{m 1} & r_{m 2} & \ldots & r_{m n}
\end{array}\right]
$$

Step 3: Create the weighted normalized matrix (V). Taking the weights of criteria into account, weighted normalized matrix is established by multiplying the normalized decision matrix and the weights.

$$
v_{i j}=w_{j} r_{i j} \quad i=1,2, \ldots, \mathrm{m} ; j=1,2, \ldots, \mathrm{n}
$$

Step 4: Decide PIS and NIS. PIS and NIS are determined as follows:

$\operatorname{PIS}\left(v_{j}^{*}\right)=\left\{\left(\begin{array}{c}\max \\ i\end{array} v_{i j} \mid j \in J\right.\right.$ benefit criteria $),\left(\begin{array}{c}\min \\ i\end{array} v_{i j} \mid j \in J\right.$ cost criteria $\}$

$\operatorname{NIS}\left(v_{j}^{-}\right)=\left\{\left(\begin{array}{c}\min \\ i\end{array} v_{i j} \mid j \in J\right.\right.$ benefit criteria $),\left(\begin{array}{c}\max \\ i\end{array} v_{i j} \mid j \in J\right.$ cost criteria $\}$

where " $J "$ shows the utility (maximization) and " $J$ " shows the loss (minimization) values.

Step 5: Calculate Euclidian distances from PIS and NIS for each alternative. Euclidean distance is employed to reveal the separation values of the alternatives from the PIS and NIS. The seperation values $S_{i}^{*}$ and $S_{i}^{-}$for the decision alternatives are obtained respectively as follows:

$$
\begin{array}{ll}
S_{i}^{*}=\sqrt{\sum_{j=1}^{n}\left(v_{i j}-v_{j}^{*}\right)^{2}} & i=1,2, \ldots, m \\
S_{i}^{-}=\sqrt{\sum_{j=1}^{n}\left(v_{i j}-v_{j}^{-}\right)^{2}} & i=1,2, \ldots, m
\end{array}
$$

Step 6: Obtain the relative closeness for alternatives: In this step, the relative closeness $C^{*}$ to the ideal solution for each alternative is obtained in the following.

$$
C_{i}^{*}=\frac{S_{i}^{-}}{S_{i}^{-}+S_{i}^{*}}
$$

$$
i=1,2, \ldots, m
$$

Step 7: Rank the alternatives: The possible alternatives can be prioritized considering the descending order of $C^{*}$. The higher the value of the relative closeness, the higher the ranking.

\subsection{TODIM}

The TODIM method based on prospect theory is developed by Lourenzutti and Krohling (2013). TODIM investigates the relative dominance of each alternative over the others. Let A $=\left(A_{1}, A_{2}, \ldots A_{m}\right)$ be a set of alternatives where $A_{i}(\mathrm{i}=1,2, \ldots, \mathrm{m})$ shows $i^{\text {th }}$ alternative and $\mathrm{C}=\left(C_{1}\right.$, 
$\left.C_{2}, \ldots C_{n}\right)$ be set of criteria where $C_{J}(j=1,2, \ldots, n)$ shows $j^{\text {th }}$ criteria. The mathematical operations used in the application of TODIM is summarized as follows:

Step 1. Establish the dominance degree of the alternative $A_{i}$ over each alternative $A_{k}$ considering the criterion $C_{j}$ by:

$\emptyset_{j}\left(A_{i}, A_{k}\right)=\left\{\begin{array}{cccc}\sqrt{\frac{w_{j r}\left(x_{i j}-x_{k j}\right)}{\sum_{j=1}^{n} w_{j r}}}, & \text { if } & x_{i j}-x_{k j}>0 \\ 0, & \text { if } & x_{i j}-x_{k j}=0 \\ \frac{1}{-\theta} \sqrt{\left(\sum_{j=1}^{n} w_{j r}\right) \frac{\left(x_{k j}-x_{i j}\right)}{w_{j r}}} & \text { if } & x_{i j}-x_{k j}<0\end{array}\right.$

where the parameter $\theta$ shows the attenuation factor of the losses; The smaller $\theta$, the higher the degree to which DMs prefer risk avoidance. If $\theta>1$ the losses are attenuated while if $\theta<1$ the losses are amplified.

$w_{j r}=\frac{w_{j}}{w_{r}}$ is the relative weight of the criterion $C_{j}$ to $C_{r}$ and $w_{r}=\max _{j=1}^{n} w_{j}$.

Step 2. The overall dominance matrix $\left(A_{i j}, A_{t j}\right)_{m x m}$ of the alternative $A_{i}$ over each alternative $A_{t}$ is then obtained as:

$\delta\left(A_{i}, A_{k}\right)=\sum_{j=1}^{n} \emptyset_{j}\left(A_{i}, A_{k}\right) \quad(i, k=1,2, \ldots, m)$

Step 3. The overall performance value of each alternative $A_{i}(i=1,2, \ldots, m)$ is obtained as:

$\xi\left(A_{i}\right)=\frac{\sum_{k=1}^{m} \delta\left(A_{i}, A_{k}\right)-\min _{i}\left[\sum_{k=1}^{m} \delta\left(A_{i}, A_{k}\right)\right]}{\max _{i}\left[\sum_{k=1}^{m} \delta\left(A_{i}, A_{k}\right)\right]-\min _{i}\left[\sum_{\mathrm{k}=1}^{m} \delta\left(A_{i}, A_{k}\right)\right]} \quad i, k=1,2, \ldots, m$

Thus, the greater the overall value $\xi\left(A_{i}\right)$, the better the alternative $\left(A_{i}\right)$.

\section{Proposed Approach}

In this section, a hybrid approach based on TODIM and TOPSIS under PCF environment is presented utilizing advantages of two well-known MCDM methods.

Assume, we face with decision making problem involving $m$ alternatives $\left(A_{1}, A_{2}, \ldots A_{m}\right)$ that must be evaluated by the group of $k \mathrm{DMs}: \mathrm{DM}_{1}, \mathrm{DM}_{2}, \ldots . \mathrm{DM}_{\mathrm{k}}$, with respect to $n$ criteria $\left(C_{1}, C_{2}\right.$, $\ldots, C_{n}$ ). The performance or rating of each alternative $i$ considering each criterion $j$ is determined based on PCFN and it can be expressed as $p_{c i j}(i=1, \ldots m ; j=1, \ldots, n)$.

The proposed approach is introduced in the following:

Step 1. Form a decision making group and determine the possible alternatives available and, set of the most important criteria for evaluating the alternatives. In this step, an expert (DM) 
group is constituted to determine the possible alternative set and evaluation criteria for alternatives in decision making problem.

Step 2. Build the decision matrix. The PCF decision matrix $P^{k}=\left(p_{c i j}\right)_{m x n}$ is established for each DM to determine alternative rankings with respect to criteria. The performance or rating of each alternative $i$ in each criterion $j$ is determined by $k^{\text {th }}$ DM based on PCFNs.

$$
\begin{aligned}
& P^{k}=\left[p_{c i j}{ }^{k}\right]_{m x n} \\
& =\left[\begin{array}{ccc}
p_{\mathrm{c} 11}^{k} & p_{\mathrm{c} 12}^{k} \cdots & p_{\mathrm{c} 1 n}^{k} \\
p_{\mathrm{c} 21}^{k} & p_{\mathrm{c} 22}^{k} \cdots & p_{\mathrm{c} 2 n}^{k} \\
\vdots & \vdots & \vdots \\
p_{c m 1}^{k} & p_{c m 2}^{k} & p_{c m n}^{k}
\end{array}\right]
\end{aligned}
$$

where $p_{c i j}^{k}=\left(\left[a_{i j}^{k}, b_{i j}^{k}, \lambda_{i j}^{k}\right],\left[\tilde{a}_{i j}^{k}, \tilde{b}_{i j}^{k}, \mu_{i j}^{k}\right]\right)$ is the PCFN of alternative $i$ with respect to criterion $j$ evaluated by DM k.

Step 3. Aggregate decision matrices. To collect of DMs opinions in one decision matrix, PCFWG aggregation operator is applied as shown in Equation (8). Aggregate decision matrix $P^{A}=\left[p_{c i j}\right]_{m x n}$ is obtained.

Step 4. Determine the weights of criteria. The weight of criteria are obtained by employing the approach presented from Roy et al. (2019). The procedure applied for determining weight of criteria is as follows:

Assume $w=\left(w_{1}, w_{2}, \ldots, w_{n}\right)^{T}$ are the weights of the criteria $C_{j}, j=1,2, \ldots, n$, where $w_{j}>$ $0\left(\forall_{j}\right), \sum_{j=1}^{n} w_{j}=1$ and $0 \leq w_{j} \leq 1$.

The five basic ranking form for criteria are employed as:

(1) A weak ranking: $H_{1}=\left\{w_{i}>w_{j}\right\}$;

(2) A strict ranking: $H_{2}=\left\{w_{i}-w_{j} \geq \beta_{j} \mid \beta_{j}>0\right\}$;

(3) A ranking of differences: $H_{3}=\left\{w_{i}-w_{j} \geq w_{k}-w_{l} \mid j \neq k \neq l\right\}$;

(4) A ranking with multiplies: $H_{4}=\left\{w_{i}>\beta_{j} w_{j} \mid 0 \leq \beta_{j} \leq 1\right\}$;

(5) An interval form: $H_{5}=\left\{\beta_{i} \geq w_{i} \leq \beta_{j}+\delta_{i} \mid 0 \leq \beta_{i} \leq \beta_{j}+\delta_{i}\right\}$;

The distance between the alternative $A_{i}$ and other alternatives under the criterion $C_{j}$ is determined as: 
$D_{i j}=\frac{1}{m-1} \sum_{g=1, g \neq i}^{m} d_{H}\left(x_{i j}, x_{g j}\right) ; i=1,2, \ldots m, \quad j=1,2, \ldots, n$

The overall distance measures of all the alternatives with regard to the criterion $C_{j}$ are shown in Equation (26).

$D_{j}=\frac{1}{m-1} \sum_{i=1}^{m} \sum_{g=1, g \neq i}^{m} d_{H}\left(x_{i j}, x_{g j}\right) ; j=1,2, \ldots, n$

Thus, the weight vector of criteria $w=\left(w_{1}, w_{2}, \ldots, w_{n}\right)^{T}$ is obtained to maximize $D_{w}$ in the optimization model shown as in the following:

$$
\left\{\begin{array}{c}
\text { Maximize } D(w)=\frac{1}{m-1} \sum_{i=1}^{m} \sum_{g=1, g \neq i}^{m} d_{H}\left(x_{i j}, x_{g j}\right) w_{j} \\
\text { subject to } \sum_{j=1}^{n} w_{j}=1, w_{j} \geq 0 j=1,2, \ldots, n
\end{array}\right.
$$

Step 5. Compute relative weights of the criteria. Once the weight of criteria $\left(w_{1}, w_{2}, \ldots, w_{n}\right)$ are determined using Equation (25-27), we compute the relative weight of each criterion considering the weight of the reference criterion as:

$w_{j r}=\frac{w_{j}}{w_{r}}$

where $w \mathrm{j}$ is the weight of the criterion of $\mathrm{cj}$, we can identify the reference criterion $w_{r}$ as: $w_{r}=\max \left\{w_{j} \mid w_{1}, w_{2}, \ldots, w_{n}\right\} \quad, 0 \leq w_{j r} \leq 1$.

Step 6. Normalize the decision matrix. If there are two kinds of criteria (cost and benefit), the PCF matrix is normalized using Equation (30). Normalized matrix is shown as:

$\left[p_{i j}^{\prime}\right]_{m x n}=\left[\begin{array}{ccc}p_{11}^{\prime} & p_{12}^{\prime} \cdots & p_{1 n}^{\prime} \\ p_{21}^{\prime} & p_{22}^{\prime} \cdots & p_{2 n}^{\prime} \\ \vdots & \vdots & \vdots \\ p_{m 1}^{\prime} & p_{m 2}^{\prime} & p_{m n}^{\prime}\end{array}\right]$

$p_{i j}^{\prime}=\left\{\begin{array}{cc}p_{c_{i j}} & \text { for benefit criteria } \\ p_{c i j}^{c} & \text { for cost criteria }\end{array}\right.$

where

$p_{c_{i j}}=\left(\left[a_{i j}, \mathrm{~b}_{i j}, \lambda_{i j}\right],\left[\tilde{a}_{i j}, \tilde{\mathrm{b}}_{i j}, \mu_{i j}\right]\right)$

$p_{i j}^{c}=\left(\left[\tilde{a}_{i j}, \tilde{\mathrm{b}}_{i j}, \mu_{i j}\right],\left[a_{i j}, \mathrm{~b}_{i j}, \lambda_{i j}\right]\right)$ 
Step 7. Establish the dominance value of the alternatives. To obtain the dominance value of each alternative for constructing dominance matrix, the score of each alternative option considering criteria and the distance measures between alternatives are calculated using Equation (9) and Equation (10). The dominance degree of the alternatives are determined by applying Equation (31).

$\phi_{j}\left(A_{i}, A_{t}\right)=\left\{\begin{array}{cl}\sqrt{\frac{w_{j r} d\left(p_{i j}^{\prime}, p_{t j}^{\prime}\right)}{\sum_{j=1}^{n} w_{j r}}} & \text { if score } p_{i j}^{\prime}>\text { score } p_{t j}^{\prime} \\ 0 & \text { if score } p_{i j}^{\prime}=\text { score } p_{t j}^{\prime} \\ \frac{1}{\theta} \sqrt{\sum_{j=1}^{n} w_{j r} \frac{d\left(p_{i j}^{\prime}, p_{t j}^{\prime}\right)}{w_{j r}}} & \text { if score } p_{i j}^{\prime}<\text { score } p_{t j}^{\prime}\end{array}\right.$

As a result, the dominance matrix is obtained as

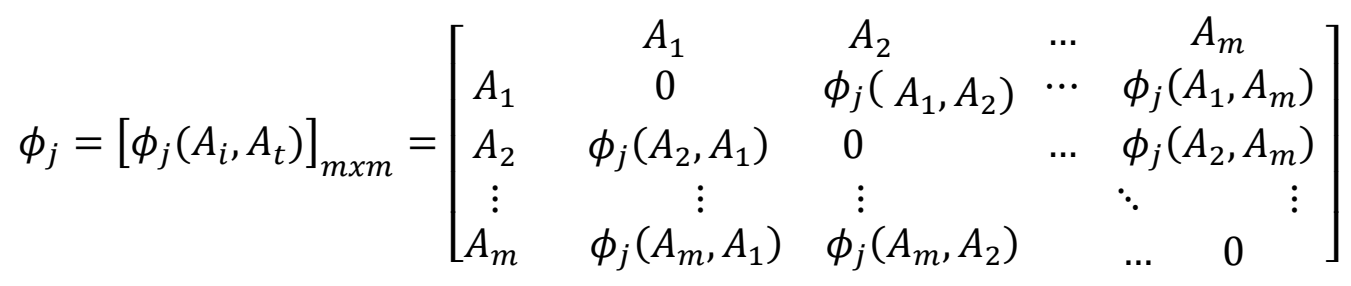

where $\phi_{j}\left(A_{i}, A_{t}\right)$ shows the degree of $A i$ over each alternative $A_{t}$ taking into account $C_{j}$.

Step 8. Obtain the collective overall dominance degree of the alternatives. The collective overall dominance degree of the alternative $A_{i}$ over each alternative $A_{k}$ under the criterion $\mathrm{C}_{\mathrm{j}}$ is computed by employing Equation (33):

$$
\delta_{j}\left(A_{i}\right)=\sum_{t=1}^{m} \phi_{j}\left(A_{i}, A_{t}\right) \quad \forall i, j
$$

The obtained total dominance matrix is shown as follows:

$$
\begin{aligned}
& D=\left[D_{i j}\right]_{m x n} \\
& =\left[\begin{array}{ccccc} 
& & & \\
& C_{1} & C_{2} & \cdots & C_{n} \\
A_{1} & \sum_{t=1}^{m} \phi_{1}\left(A_{1}, A_{t}\right) & \sum_{t=1}^{m} \phi_{2}\left(A_{1}, A_{t}\right) & \cdots & \sum_{t=1}^{m} \phi_{n}\left(A_{1}, A_{t}\right) \\
A_{2} & \sum_{t=1}^{m} \phi_{1}\left(A_{2}, A_{t}\right) & \sum_{t=1}^{m} \phi_{2}\left(A_{2}, A_{t}\right) & \cdots & \sum_{t=1}^{m} \phi_{1}\left(A_{2}, A_{t}\right) \\
\vdots & \vdots & \vdots & \ddots & \vdots \\
A_{m} & \sum_{t=1}^{m} \phi_{1}\left(A_{m}, A_{t}\right) & \sum_{t=1}^{m} \phi_{2}\left(A_{m}, A_{t}\right) & \sum_{t=1}^{m} \phi_{n}\left(A_{m}, A_{t}\right)
\end{array}\right]
\end{aligned}
$$

Step 9. Determine PIS and NIS. By employing Equations (35)-(36), PIS $\left(O^{*}\right)$ and NIS $\left(O^{-}\right)$ are obtained, respectively. 


$$
\begin{aligned}
& O_{j}^{*}=\left(O_{1}^{*}, O_{2}^{*}, \ldots, O_{n}^{*}\right)=\left(\max _{i 1}, \max _{i 2}, \ldots \ldots \ldots, \max _{i n}\right. \\
& m \quad m \quad m \\
& O_{j}^{-}=\left(O_{1}^{-}, O_{2}^{-}, \ldots, O_{n}^{-}\right)=\left(\min D_{i 1}, \min D_{i 2}, \ldots \ldots \ldots, \min D_{i n}\right. \\
& i=1 \quad i=1 \quad i=1
\end{aligned}
$$

Step 10. Calculate the deviation values for decision alternatives. The Euclidean distance of each alternative to the $O^{*}$ and $O^{-}$is computed by employing Equations (37-38), respectively. The closeness coefficient $\left(C C_{i}\right)$ to the ideal solution is obtained using Equation (39). The alternative has the maximum value of $\mathrm{CC}$ is nominated as the most desirable alternative.

$$
\begin{aligned}
S_{i}^{*}=\sqrt{\sum_{j=1}^{m}\left(D_{i j}-O_{j}^{*}\right)^{2}} & \text { for } \forall i 1,2, \ldots m \\
S_{i}^{-}=\sqrt{\sum_{j=1}^{m}\left(D_{i j}-O_{j}^{-}\right)} & \text {for } \forall i 1,2, \ldots, m \\
C C_{i}=\frac{S_{i}^{-}}{S_{i}^{-}+S_{i}^{*}} & \text { for } \forall i=1,2, \ldots, m
\end{aligned}
$$

\section{Case Study}

The proposed method is implemented for vendor-supplied software package selection problem in a fuel oil company carries out its operations in Turkey. The company is working in the fields of purchasing and importing industrial fuel oils, petroleum and petroleum products. Operation managers of the company will make a decision in the selection of vendor supplied software system for providing the flow of information between departments effectively, decreasing costs and stocks, developing supplier relationships and improving customer service. The software selection process is complex and risk-prone due to many conflicting factors that may affect the efficiency of the processes during decision making. Since the selection of suitable software would increase the competitive advantage of the company, a project team consists of four managers assigned as the DMs with work experiences of 5-12 years and academic, engineering and IT backgrounds was constituted. The project team determined some qualitative and quantitative criteria to evaluate alternative software packages based on their experiences, and related studies in the literature.

Accordingly, the evaluation criteria were determined as "Satisfaction of needs" (C1), "Ease of use of interface" (C2), “Adapt to DevOps processes" (C3), "Integration of TFS" (C4), "DSLA for maintenance" (C5), "Price" (C6), "Education support" (C7), and "Technical competence" 
(C8). The project team in the company evaluated the four software vendors according to the determined criteria. The flowchart of the proposed method is represented in Figure 1.

The application procedure of the proposed approach is as follows:

Step 1. Constitute decision making group and establish decision making matrices. Once the vendor supplied software package alternatives and evaluation criteria are determined, the decision-making group including DMs is formed. Accordingly four vendor supplied software alternatives and eight evaluation criteria are obtained for the application of the proposed approach. Individual decision matrix for each DM is constructed based on their opinions.

Step 2. Collect individual matrices and obtain aggregated decision matrix. The individual decision matrices are aggregated by applying Equation (8). As a result, we obtain one decision matrix as shown in Table 1.

Step 3. Determine the weights and relative weights of criteria. While the weight vector are determined using Equations (25-27), relative weights of criteria are obtained using Equation (28).

Step 4. Normalize decision matrix. Considering maximization and minimization criteria, decision matrix is normalized using Equation (30).

Step 5. Determine the dominance degree of each alternative over the others. Once the score value of each element for decision matrix and distance value of each alternative is calculated using Equation (9-10), the dominance degree of each alternative over the other alternatives is determined by conducting Equation (31). The dominance degree matrix under first three criteria is shown in Table 2.

Step 6. Obtain the overall dominance matrix. Based on Equation (33), the overall dominance degree of each alternative over the other alternatives can be calculated by the sum of the elements of the dominance degree matrices. The results are shown in Table 3.

Step 7. Identify $O^{*}$ and $O^{-}$. In this step we determine the $O^{*}$ (extreme performance on each criterion) and the $\mathrm{O}^{-}$(reverse extreme performance on each criterion) considering maximization and minimization criteria as in Equation (35-36). $O^{*}$ and $\mathrm{O}^{-}$for alternative options are shown in Table 4. 


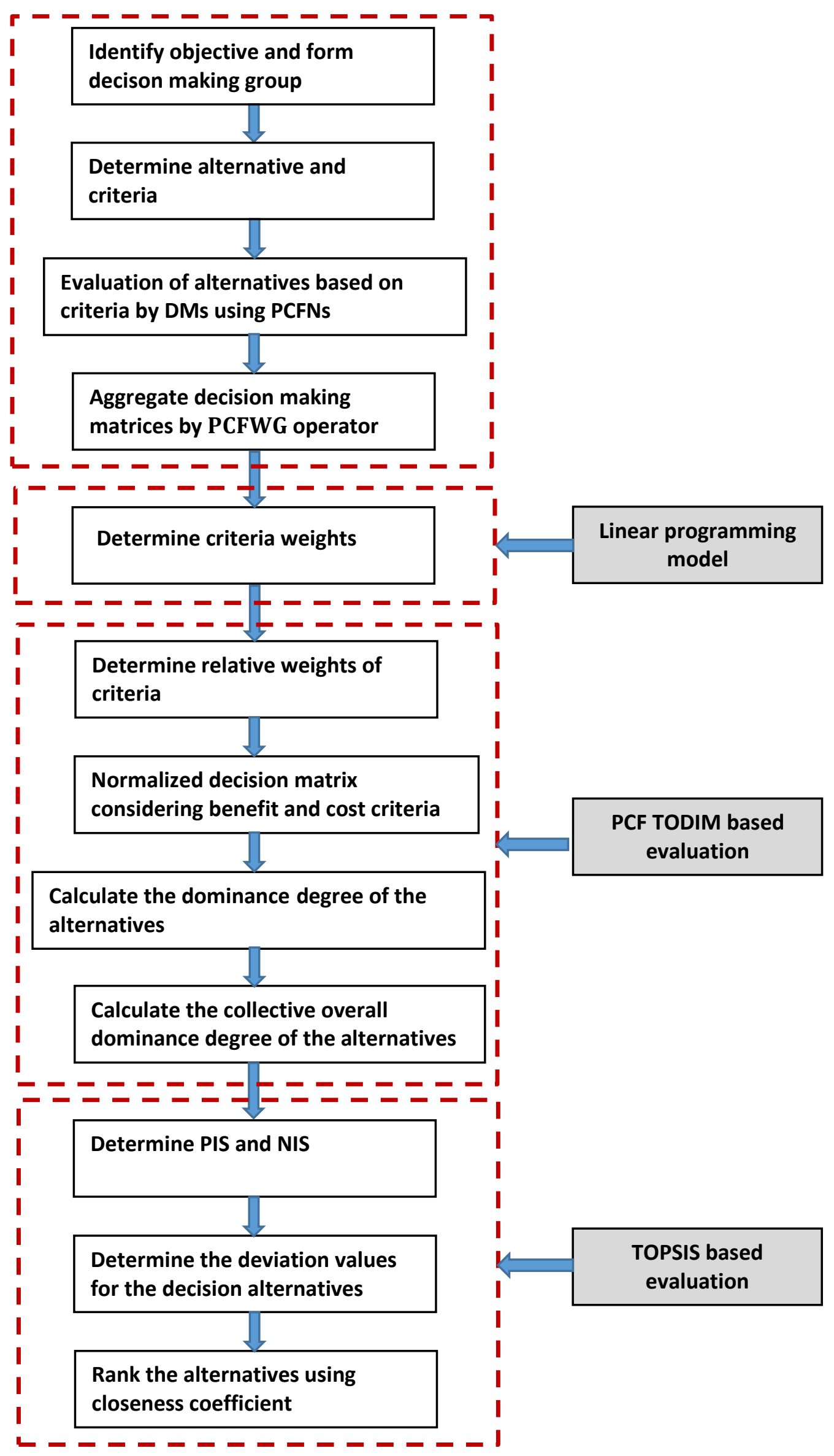

Figure 1. The flowchart of the proposed approach. 
Table 1. Collective assessments of four alternatives based on each criterion

\begin{tabular}{|c|c|c|c|c|}
\hline \multirow{2}{*}{ Criteria } & Projects & 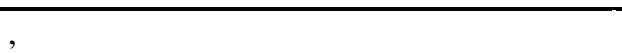 & \multicolumn{2}{|l|}{, } \\
\hline & A1 & $\mathrm{A} 2$ & A3 & A4 \\
\hline $\mathrm{C} 1$ & $(\langle[0.52,0.72] ; 0.57]\rangle,\langle[0.45,0.63] ; 0.76]\rangle)$ & $(\langle[0.46,0.74] ; 0.59]\rangle,\langle[0.45,0.63] ; 0.75]\rangle)$ & $(\langle[0.41,0.71] ; 0.57]\rangle,\langle[0.48,0.63] ; 0.66]\rangle)$ & $(\langle[0.41,0.71] ; 0.57]\rangle,\langle[0.48,0.63] ; 0.66]\rangle)$ \\
\hline $\mathrm{C} 2$ & $(\langle[0.42,0.67] ; 0.45]\rangle,\langle[0.33,0.53] ; 0.55]\rangle)$ & $(\langle[0.35,0.49] ; 0.63]\rangle,\langle[0.72,0.86] ; 0.65]\rangle)$ & $(\langle[0.37,0.67] ; 0.69]\rangle,\langle[0.38,0.63] ; 0.55]\rangle)$ & $(\langle[0.37,0.67] ; 0.69]\rangle,\langle[0.38,0.63] ; 0.55]\rangle)$ \\
\hline $\mathrm{C} 3$ & $(\langle[0.44,0.65] ; 0.56]\rangle,\langle[0.43,0.68] ; 0.63]\rangle)$ & $(\langle[0.39,0.67] ; 0.54]\rangle,\langle[0.31,0.53] ; 0.76]\rangle)$ & $(\langle[0.47,0.75] ; 0.24]\rangle,\langle[0.39,0.63] ; 0.87]\rangle)$ & $(\langle[0.47,0.75] ; 0.24]\rangle,\langle[0.39,0.63] ; 0.87]\rangle)$ \\
\hline $\mathrm{C} 4$ & $(\langle[0.47,0.77] ; 0.57]\rangle,\langle[0.46,0.58] ; 0.64]\rangle)$ & $(\langle[0.38,0.61] ; 0.69]\rangle,\langle[0.38,0.58] ; 0.43]\rangle)$ & $(\langle[0.47,0.65] ; 0.64]\rangle,\langle[0.43,0.63] ; 0.58]\rangle)$ & $(\langle[0.47,0.65] ; 0.64]\rangle,\langle[0.43,0.63] ; 0.58]\rangle)$ \\
\hline $\mathrm{C} 5$ & $(\langle[0.72,0.87] ; 0.32]\rangle,\langle[0.28,0.43] ; 0.79]\rangle)$ & $(\langle[0.56,0.74] ; 0.63]\rangle,\langle[0.41,0.61] ; 0.41]\rangle)$ & $(\langle[0.41,0.71] ; 0.47]\rangle,\langle[0.46,0.58] ; 0.68]\rangle)$ & $(\langle[0.41,0.71] ; 0.47]\rangle,\langle[0.46,0.58] ; 0.68]\rangle)$ \\
\hline C6 & $(\langle[0.39,0.57] ; 0.63]\rangle,\langle[0.35,0.68] ; 0.58]\rangle)$ & $(\langle[0.47,0.67] ; 0.52]\rangle,\langle[0.43,0.63] ; 0.66]\rangle)$ & $(\langle[0.57,0.72] ; 0.25]\rangle,\langle[0.48,0.58] ; 0.73]\rangle)$ & $(\langle[0.57,0.72] ; 0.25]\rangle,\langle[0.48,0.58] ; 0.73]\rangle)$ \\
\hline $\mathrm{C} 7$ & $(\langle[0.46,0.71] ; 0.46]\rangle,\langle[0.43,0.63] ; 0.66]\rangle)$ & $(\langle[0.47,0.67] ; 0.61]\rangle,\langle[0.41,0.63] ; 0.46]\rangle)$ & $(\langle[0.47,0.67] ; 0.67]\rangle,\langle[0.43,0.63] ; 0.58]\rangle)$ & $(\langle[0.47,0.67] ; 0.67]\rangle,\langle[0.43,0.63] ; 0.58]\rangle)$ \\
\hline $\mathrm{C} 8$ & $(\langle[0.37,0.62] ; 0.71]\rangle,\langle[0.43,0.68] ; 0.63]\rangle)$ & $(\langle[0.55,0.77] ; 0.54]\rangle,\langle[0.42,0.63] ; 0.66]\rangle)$ & $(\langle[0.57,0.75] ; 0.22]\rangle,\langle[0.48,0.63] ; 0.79]\rangle)$ & $(\langle[0.57,0.75] ; 0.22]\rangle,\langle[0.48,0.63] ; 0.79]\rangle)$ \\
\hline
\end{tabular}

Table 2. Dominance degree matrix of alternatives.

\begin{tabular}{lrrrr}
\hline $\boldsymbol{\Phi}_{1}$ & $\mathrm{~A} 1$ & $\mathrm{~A} 2$ & $\mathrm{~A} 3$ & $\mathrm{~A} 4$ \\
\hline $\mathrm{A} 1$ & 0.0000 & 0.0676 & 0.1023 & 0.2917 \\
$\mathrm{~A} 2$ & -0.1249 & 0.0000 & 0.0968 & 0.2172 \\
$\mathrm{~A} 3$ & -0.1890 & -0.1789 & 0.0000 & 0.1984 \\
$\mathrm{~A} 4$ & -0.4061 & -0.4014 & -0.3668 & 0.0000 \\
$\boldsymbol{\Phi}_{2}$ & & & & 0.1503 \\
$\mathrm{~A} 1$ & 0.0000 & 0.2190 & 0.1248 & -0.4381 \\
$\mathrm{~A} 2$ & -0.4682 & 0.0000 & -0.4147 & 0.0997 \\
$\mathrm{~A} 3$ & -0.2668 & 0.1939 & 0.0000 & 0.0000 \\
$\mathrm{~A} 4$ & -0.3214 & 0.2049 & -0.2133 & 3.0133 \\
$\boldsymbol{\Phi}_{3}$ & & & & 0.1188 \\
$\mathrm{~A} 1$ & 0.0000 & -0.3013 & -3.0375 & 0.1339 \\
$\mathrm{~A} 2$ & 0.1025 & 0.0000 & -0.5711 & 0.0000 \\
$\mathrm{~A} 3$ & 0.1306 & 0.1216 & 0.0000 & -0.6291 \\
$\mathrm{~A} 4$ & 0.1021 & -0.5581 & & \\
\hline
\end{tabular}


Table 3. Overall dominance of vendor supplied software alternatives.

\begin{tabular}{|c|c|c|c|c|}
\hline$\delta_{j}$ & $\mathrm{~A} 1$ & A2 & A3 & A4 \\
\hline $\mathrm{C} 1$ & 0.3896 & 0.1891 & -0.1695 & -1.1744 \\
\hline $\mathrm{C} 2$ & 0.4942 & -1.3211 & 0.0269 & -0.3299 \\
\hline $\mathrm{C} 3$ & -9.0646 & -0.3497 & 0.3863 & -1.0852 \\
\hline $\mathrm{C} 4$ & 0.9078 & -4.3861 & -1.8214 & -8.5814 \\
\hline $\mathrm{C} 5$ & 1.4015 & -4.1248 & -1.3231 & -2.4174 \\
\hline C6 & 1.6719 & -0.4661 & -2.2487 & -1.3829 \\
\hline C7 & 2.3013 & -0.3605 & -0.0555 & -1.3597 \\
\hline $\mathrm{C} 8$ & -7.7580 & -0.2453 & 0.3873 & -0.4498 \\
\hline
\end{tabular}

Table 4. $O^{*}$ and $O^{-}$for vendor supplied software alternatives.

\begin{tabular}{rcccc}
\hline Criteria & Alternative & $O^{*}$ & Alternative & $O^{-}$ \\
\hline C1 & A1 & 0.389 & A4 & -1.174 \\
C2 & A1 & 0.494 & A2 & -1.321 \\
C3 & A3 & 0.386 & A1 & -9.064 \\
C4 & A1 & 0.907 & A4 & -8.581 \\
C5 & A1 & 1.401 & A2 & -4.124 \\
C6 & A1 & 1.671 & A3 & -2.248 \\
C7 & A1 & 2.301 & A4 & -1.359 \\
C8 & A3 & 0.387 & A1 & -7.759 \\
\hline
\end{tabular}

Step 8. Obtain the separation measures from the $O^{*}$ and the $O^{-}$. The separation of each alternative from $O^{*}$ and $O^{-}$is calculated by conducting Euclidean distance as shown in Equation (37-38). The results are shown in Table 5.

Step 9-10. Obtain the $\mathrm{CC}$ to the Ideal Solution and rank the alternatives. $\mathrm{CC}$ of each vendor supplied software alternative is obtained by applying Equation (39). The larger CC means the better alternative. CC values of each vendor supplied software package alternative and the ranking order of the alternatives are represented in Table 5. According to results, the scores of vendor supplied software alternatives in descending order are A3>A2>A1>A4. Accordingly, A3 has higher priority as it has highest CC.

Table 5. CCs and ranking order of software alternatives.

\begin{tabular}{ccccc}
\hline Alternative & $\boldsymbol{S}^{*}$ & $\boldsymbol{S}^{-}$ & CC & Rank \\
\hline A1 & 12.47 & 12.453 & 0.4995 & 3 \\
A2 & 8.631 & 12.491 & 0.5913 & 2 \\
A3 & 6.027 & 14.620 & 0.7080 & 1 \\
A4 & 11.54 & 11.033 & 0.4886 & 4 \\
\hline
\end{tabular}

\subsection{Sensitivity and Comparative Analysis}


In this subsection firstly, sensitivity analysis is applied to indicate the influence of the attenuation parameter $\theta$ on the produced results of proposed integrated TODIM and TOPSIS method under PCF environment. The proposed method is constructed considering rational behaviors of DMs toward risk such as risk aversion, risk seeking etc. Therefore, risk factor is expressed with different values of the variable $\theta$ to show DMs different attitude towards to risks in real world applications. Accordingly, the attenuation parameter $\theta$ reflect of the DMs attitude about losses. $\theta<1$ refers to DMs' risk averse attitude and the losses are amplified. However, $\theta>1$ refers to DMs' risk seeker attitude and the losses are attenuated. While $\theta$ shows different attitudes of DMs towards to risks and it is suggested to have value between 1 and 2.5 in the literature (Kahneman and Tversky, 1992).

Thus, in the sensitivity analysis, we altered the value of the attenuation parameter $\theta$ between 1 and 2.5. Accordingly, with the change of the attenuation factor value $\theta$, the ranking of four vendor-supplied software systems is changed as shown in Table 6. These results showed that the ranking of four vendor-supplied software systems is sensitive to the value of $\theta$ parameter. To visualize the influence of different values of parameter $\theta$ on the ranking results, the results are shown in Figure 2. When $\theta$ parameter changes from 0 to 2.0 the ranking of alternatives is obtained as $\mathrm{A} 3>\mathrm{A} 2>\mathrm{A} 4>\mathrm{A} 1$. The smaller the $\theta$ value shows the higher risk aversion of DMs against to the losses. When $\theta>2$ the ranking changes as $\mathrm{A} 3>\mathrm{A} 2>\mathrm{A} 1>\mathrm{A} 4$. The results show that the psychological behavior of DMs effects the ranking of alternatives. As a result, since the final ranking of alternatives are sensitive to the $\theta$ parameter value chosen according to psychological behavior of DMs, suitable $\theta$ parameter value should be selected considering DMs' risk attitudes.

Table 6. CC of alternatives based on different $\theta$ parameters.

\begin{tabular}{cccccc}
\hline \multicolumn{7}{c}{ Closeness coefficients (CC) } \\
\hline Scenario & A1 & A2 & A3 & A4 & Ranking order \\
\hline$\theta=1.0$ & 0.474 & 0.632 & 0.766 & 0.518 & $\mathrm{~A} 3>\mathrm{A} 2>\mathrm{A} 4>\mathrm{A} 1$ \\
$\theta=1.2$ & 0.477 & 0.626 & 0.757 & 0.514 & $\mathrm{~A} 3>\mathrm{A} 2>\mathrm{A} 4>\mathrm{A} 1$ \\
$\theta=1.4$ & 0.480 & 0.620 & 0.749 & 0.510 & $\mathrm{~A} 3>\mathrm{A} 2>\mathrm{A} 4>\mathrm{A} 1$ \\
$\theta=1.6$ & 0.484 & 0.615 & 0.741 & 0.506 & $\mathrm{~A} 3>\mathrm{A} 2>\mathrm{A} 4>\mathrm{A} 1$ \\
$\theta=1.8$ & 0.487 & 0.609 & 0.734 & 0.502 & $\mathrm{~A} 3>\mathrm{A} 2>\mathrm{A} 4>\mathrm{A} 1$ \\
$\theta=2.0$ & 0.491 & 0.604 & 0.726 & 0.498 & $\mathrm{~A} 3>\mathrm{A} 2>\mathrm{A} 4>\mathrm{A} 1$ \\
$\theta=2.2$ & 0.495 & 0.599 & 0.718 & 0.494 & $\mathrm{~A} 3>\mathrm{A} 2>\mathrm{A} 1>\mathrm{A} 4$ \\
$\theta=2.4$ & 0.497 & 0.593 & 0.711 & 0.490 & $\mathrm{~A} 3>\mathrm{A} 2>\mathrm{A} 1>\mathrm{A} 4$ \\
$\theta=2.5$ & 0.499 & 0.591 & 0.708 & 0.488 & $\mathrm{~A} 3>\mathrm{A} 2>\mathrm{A} 1>\mathrm{A} 4$ \\
\hline
\end{tabular}




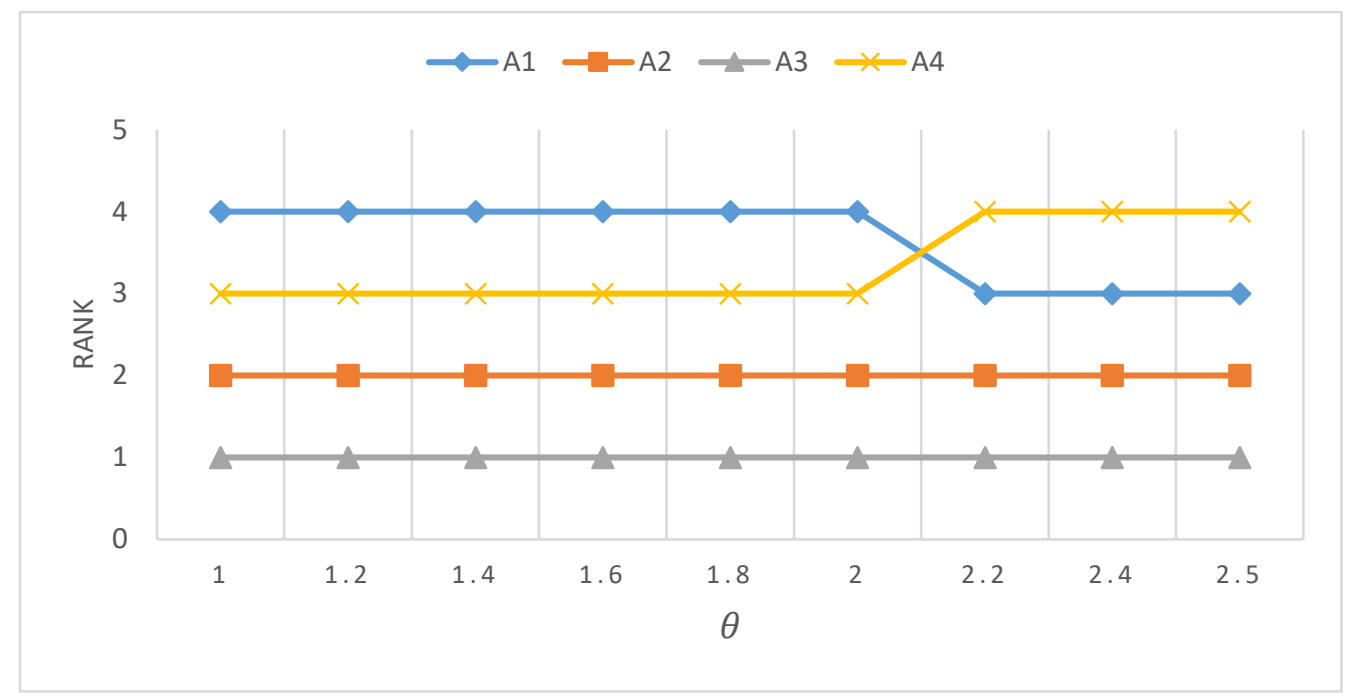

Figure 2. Ranking order of alternatives based on different $\theta$ parameters.

Then, in order to prove validity and superiority of the proposed approach, we conduct comparative analysis with the IVPF TODIM introduced by Huang and Wei (2018); IVPF TOPSIS presented by Garg (2017); PCF TOPSIS presented by Khan (2020) and Pythagorean cubic fuzzy ordered weighted geometric (PCFOWG) aggregation operator developed by Khan et al. (2019a). To apply IVPF TODIM and IVPF TOPSIS methods, PCFNs used in the proposed approach are transformed into IVPFNs removing confidence level of the attributes.

Table 7 and Figure 3 represent the ranking results of the alternatives obtained by five methods. The results reveal that the ranking of alternatives obtained by these two methods (IVPF TODIM and IVPF TOPSIS) are consistent since they perform IVPFSs. The proposed approach and other existing approaches based on PCF produces different results as expected, since they use PCFNs as the generalization of IVPFSs considering the confidence level of the attributes.

Table 7. Comparison of the ranking order of alternatives in different methods.

\begin{tabular}{|c|c|c|c|c|c|}
\hline \multicolumn{6}{|c|}{ Rank } \\
\hline Alternative & $\begin{array}{l}\text { IVPF } \\
\text { TODIM }\end{array}$ & $\begin{array}{c}\text { IVPF } \\
\text { TOPSIS }\end{array}$ & $\begin{array}{c}\text { PCF } \\
\text { TOPSIS }\end{array}$ & $\begin{array}{c}\text { PCF } \\
\text { PCFOWA }\end{array}$ & $\begin{array}{l}\text { PCF TODIM } \\
\text { based TOPSIS }\end{array}$ \\
\hline A1 & 1 & 1 & 2 & 3 & 3 \\
\hline A2 & 3 & 3 & 3 & 2 & 2 \\
\hline A3 & 2 & 2 & 1 & 1 & 1 \\
\hline A4 & 4 & 4 & 4 & 4 & 4 \\
\hline
\end{tabular}




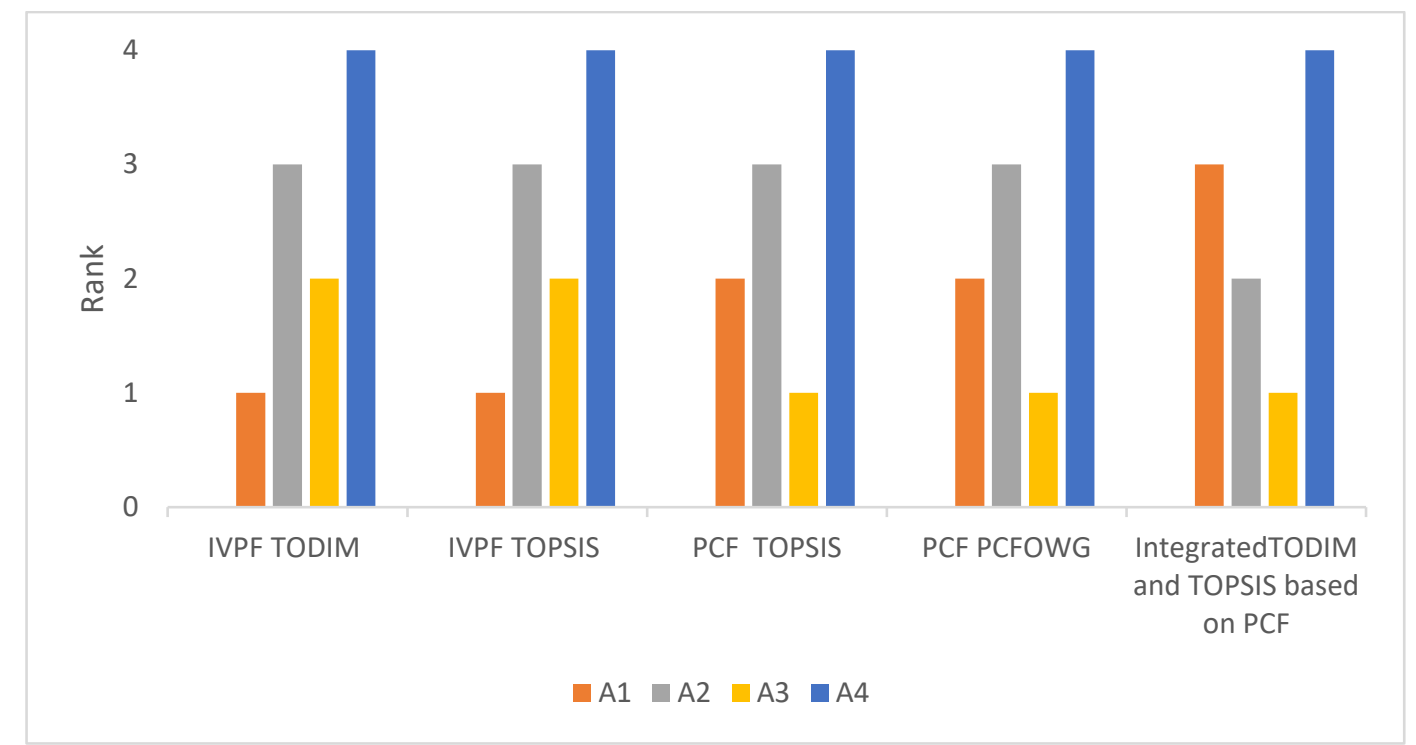

Figure 3. Visual representation for ranking order of alternatives in comparative analysis.

However, The ranking order of alternatives obtained by PCF TOPSIS, PCF PCFOWG and the proposed method are consistent in the first and the last ranking order of alternatives. The difference is seen in the ranking order between A1 and A2 in PCF TOPSIS. The main reason is that TOPSIS method is based on the assumption that DMs are completely rational. Therefore, a ranking result closer to the real situation can be obtained. In the TODIM method, on the other hand, the rationality is limited and the psychological characteristics of DMs are taken into account. As a result, since judgments of DMs in the proposed method are handled much comprehensive with PCFS by considering their psychological behavior, the ranking results obtained by the proposed approach are more accurate and reasonable. Thus, the presented comparative analysis validates the robustness and effectiveness of Integrated TODIM based TOPSIS method under PCF environment.

\section{Conclusion}

Companies need strategical management processes as they grow and enhance with the globalization. Software packages used in the companies provide ease of management in all levels throughout organization. Selection of the best suitable software package for company requires strategic decision process, since the selected software conduct essential and critical business functions. The aim of this study to select the most suitable vendor-supplied software package alternative for fuel oil Company using a new hybrid method based on TOPSIS and TODIM under PCF environment. 
TODIM is applied in this study since the evaluation process involves risk. The method generates more appropriate decision results considering DMs actual needs and risk preferences. TOPSIS method is adjusted to TODIM method to find optimum solution which has the shortest distance from the PIS and farthest distance from NIS. In addition, since PCFNs can more strongly deal with the uncertainty of DMs' judgments in the MCDM problems than the IVPFSs, the proposed method is applied based on PCFNs. As a result, the integration of these two methods under PCF environment produces feasible results by handling uncertainty in real decision making problems and taking consideration of DMs psychological behavior in risky conditions.

In order to show the influence of different values of the attenuation parameter $\theta$, we apply different $\theta$ values in Sensitivity Analysis. Since the ranking of alternatives are not constant for different $\theta$ values, determining of the parameter $\theta$ value is important issue for solving problem successfully. Lastly, comparative analysis is carried out to prove the effectiveness of the proposed method. As the PCFNs reflect DMs preferences and thoughts better, the obtained results are more accurate and reasonable. The integration of TODIM methods with other classical decision making methods using different fuzzy extensions can be suggested for further research.

\section{Compliance with ethical standards}

Conflict of interest The authors declares that they have no conflict of interest.

Ethical approval This article does not contain any studies with human participants or animals performed by any of the authors.

\section{References}

Abbas, S. Z., Ali Khan, M. S., Abdullah, S., Sun, H., \& Hussain, F. (2019). Cubic Pythagorean fuzzy sets and their application to multi-attribute decision making with unknown weight information. Journal of Intelligent \& Fuzzy Systems, (Preprint), 1-16.

Aguilar-Cisneros, J. R., Rosas-Sumano, J. J., \& Morales-Ignacio, L. A. (2017). Selection of best software engineering practices: a multi-criteria decision making approach. Advances in Social Informatics and its Applications, 47.

Arshadi Khamseh, A., \& Mahmoodi, M. (2014). A new fuzzy TOPSIS-TODIM hybrid method for green supplier selection using fuzzy time function. Advances in Fuzzy Systems, 2014.

Atanassov, K. \& Gargov, G. (1989). Interval-valued intuitionistic fuzzy sets. Fuzzy Sets and Systems Vol. 31, No. 3, pp. 343-349. 
Atanassov, K.T. (1986), “Intuitionistic fuzzy sets”, Fuzzy Sets and Systems, Vol. 20 No. 1, pp. 87-96.

Atanassov, K.T. (1995), "Remark on the intuitionistic fuzzy sets - III", Fuzzy Sets and Systems, Vol. 75, No. 3, pp. 401-402.

Aydoğan, E. K., \& Özmen, M. (2020). Travel and Tourism Competitiveness of Economies Around the World Using Rough SWARA and TODIM Method. In Strategic Innovative Marketing and Tourism (pp. 765-774). Springer, Cham.

Bakioglu, G., \& Atahan, A. O. (2021). AHP integrated TOPSIS and VIKOR methods with Pythagorean fuzzy sets to prioritize risks in self-driving vehicles. Applied Soft Computing, 99, 106948.

Beheshtinia, M. A., \& Omidi, S. (2017). A hybrid MCDM approach for performance evaluation in the banking industry. Kybernetes.

Bera, A. K., Jana, D. K., Banerjee, D., \& Nandy, T. (2019). Supplier selection using extended IT2 fuzzy TOPSIS and IT2 fuzzy MOORA considering subjective and objective factors. Soft Computing, 1-17.

Bijoyeta, R., \& Misra, S. K. (2018). An Integrated fuzzy ANP and TOPSIS methodology for software selection under MCDM perspective. International Journal of Innovative Research in Computer and Communication Engineering (IJIRCCE), 6(1).

Biswas, A., \& Sarkar, B. (2019). Interval-valued Pythagorean fuzzy TODIM approach through point operator-based similarity measures for multicriteria group decision making. Kybernetes.

Çakır, S. (2016). Selecting appropriate ERP software using integrated fuzzy linguistic preference relations-fuzzy TOPSIS method. International Journal of Computational Intelligence Systems, 9(3), 433-449.

Chen, T. Y. (2015). The inclusion-based TOPSIS method with interval-valued intuitionistic fuzzy sets for multiple criteria group decision making. Applied Soft Computing, 26, 57-73.

Eastham, J., Tucker, D. J., Varma, S., \& Sutton, S. M. (2014). PLM software selection model for project management using hierarchical decision modeling with criteria from PMBOK® knowledge areas. Engineering Management Journal, 26(3), 13-24. doi:10.1080/ 10429247.2014.11432016.

Fahmi, A., Yaqoob, N., \& Chammam, W. (2021). Maclaurin symmetric mean aggregation operators based on cubic Pythagorean linguistic fuzzy number. Journal of Ambient Intelligence and Humanized Computing, 12(2), 1925-1942.

Garg, H. (2017). A new improved score function of an interval-valued Pythagorean fuzzy set based TOPSIS method. International Journal for Uncertainty Quantification, 7(5).

Huang, Y. H., \& Wei, G. W. (2018). TODIM method for interval-valued Pythagorean fuzzy multiple attribute decision making. International Journal of Knowledge-based and Intelligent Engineering Systems, 22(4), 249-259.

Hussain, A., Lee, J. R., Ali Khan, M. S., \& Shin, D. Y. (2021). Analysis of Social Networks by Using Pythagorean Cubic Fuzzy Einstein Weighted Geometric Aggregation Operators. Journal of Mathematics, 2021. 
Hwang C.L. and Yoon, K. (1981) Multiple Attribute Decision Making: Methods and Applications, Springer-Verlag, New York.

Ilbahar, E., \& Kahraman, C. (2018). Retail store performance measurement using a novel interval-valued Pythagorean fuzzy WASPAS method. Journal of Intelligent \& Fuzzy Systems, 35(3), 3835-3846.

Ilbahar, E., Karaşan, A., Cebi, S., \& Kahraman, C. (2018). A novel approach to risk assessment for occupational health and safety using Pythagorean fuzzy AHP \& fuzzy inference system. Safety science, 103, 124-136.

Ji, P., Zhang, H.Y., Wang, J.Q., 2016. A projection-based TODIM method under multi-valued neutrosophic environments and its application in personnel selection. Neural Computing and Applications. doi:10.1007/s00521-016-2436-z.

Karsak, E. E., \& Özogul, C. O. (2009). An integrated decision making approach for ERP system selection. Expert systems with Applications, 36(1), 660-667.

Kazancoglu, Y., Burmaoglu, S. (2013). ERP Software Selection with MCDM: Application of TODIM Method, International Journal of Business Information Systems, Vol. 13, No. 4, pp. 435-452.

Khan, F., Abdullah, S., Mahmood, T., Shakeel, M., \& Rahim, M. (2019 b). Pythagorean cubic fuzzy aggregation information based on confidence levels and its application to multi-criteria decision making process. Journal of Intelligent \& Fuzzy Systems, 36(6), 5669-5683.

Khan, F., Khan, M. S. A., Shahzad, M., \& Abdullah, S. (2019 a). Pythagorean cubic fuzzy aggregation operators and their application to multi-criteria decision making problems. Journal of Intelligent \& Fuzzy Systems, 36(1), 595-607.

Khan, M. S. A., Khan, F., Lemley, J., Abdullah, S., \& Hussain, F. (2020). Extended topsis method based on Pythagorean cubic fuzzy multi-criteria decision making with incomplete weight information. Journal of Intelligent \& Fuzzy Systems, 38(2), 2285-2296.

Kim, C.S. Park, K.P. Yoon. Identifying investment opportunities for advanced manufacturing systems with comparative-integrated performance measurement International Journal of Production Economics, 50 (1997), pp. 23-33.

Krohling, R. A., Pacheco, A. G., \& dos Santos, G. A. (2019). TODIM and TOPSIS with Znumbers. Frontiers of Information Technology \& Electronic Engineering, 20(2), 283-291.

Krohling, R.A. and Pacheco, A.G.C. (2014). Interval-valued intuitionistic fuzzy TODIM", Procedia Computer Sciences, Vol. 31, pp. 236-244.

Li, M., Li, Y., Peng, Q., Wang, J., \& Yu, C. (2021). Evaluating community question-answering websites using interval-valued intuitionistic fuzzy DANP and TODIM methods. Applied Soft Computing, 99, 106918.

Li, Y., Shan, Y., \& Liu, P. (2015). An extended TODIM method for group decision making with the interval intuitionistic fuzzy sets. Mathematical Problems in Engineering, 2015. 
Liang, D., Zhang, Y., Xu, Z. and Jamaldeen A. (2019). Pythagorean fuzzy VIKOR approaches based on TODIM for evaluating internet banking website quality of Ghanaian banking industry, In: Appl. Soft Comput., Vol. 78, pp. 583-594.

Lin, Y. L., Ho, L. H., Yeh, S. L., \& Chen, T. Y. (2018). A Pythagorean fuzzy TOPSIS method based on novel correlation measures and its application to multiple criteria decision analysis of inpatient stroke rehabilitation. International Journal of Computational Intelligence Systems, 12(1), 410-425.

Liu, D., Luo, Y., \& Liu, Z. (2020). The Linguistic Picture Fuzzy Set and Its Application in Multi-Criteria Decision-Making: An Illustration to the TOPSIS and TODIM Methods Based on Entropy Weight. Symmetry, 12(7), 1170.

Lo, H. W., Shiue, W., Liou, J. J., \& Tzeng, G. H. (2020). A hybrid MCDM-based FMEA model for identification of critical failure modes in manufacturing. Soft Computing, 24(20), 1573315745 .

Lourenzutti, R., \& Krohling, R. A. (2013). A study of TODIM in a intuitionistic fuzzy and random environment. Expert Systems with Applications, 40(16), 6459-6468.

Lourenzutti, R., \& Krohling, R. A. (2014). The Hellinger distance in multicriteria decision making: An illustration to the TOPSIS and TODIM methods. Expert Systems with Applications, 41(9), 4414-4421.

Lourenzutti, R., Krohling, R. A., \& Reformat, M. Z. (2017). Choquet based TOPSIS and TODIM for dynamic and heterogeneous decision making with criteria interaction. Information Sciences, 408, 41-69.

Mulebeke, J. A. W., L. Zheng, L. (2006). Analytical network proc-ess for software selection in product development. Journal of Engineering and Technology Management, Vol. 23, No. 4, pp. $337-352$.

Nguyen, H. (2017). Interval-valued intuitionistic fuzzy failure modes and effect analysis of the system failure risk estimation. Journal of KONES, 24.

Nirmala, G., \& Uthra, G. (2016). Intuitionistic Fuzzy Analytic Hierarchy Process Based On Possibility Degree. International Journal of Pure and Applied Mathematics, 109(9), 184-192.

Ozkaya, G., \& Erdin, C. (2020). Evaluation of smart and sustainable cities through a hybrid MCDM approach based on ANP and TOPSIS technique. Heliyon, 6(10), e05052.

Peng, X. and Dai, J. (2017). Approaches to pythagorean fuzzy stochastic multi-criteria decision making based on prospect theory and regret theory with new distance measure and score function. International Journal of Intelligent Systems, Vol. 32 No. 11, pp. 1187-1214.

Peng, X.D., Yang, Y. (2016). Fundamental properties of interval-valued Pythagorean fuzzy aggregation operators, International Journal of Intelligent System 31-444-487.

Rahman, K., Abdullah, S., Ali, A., \& Amin, F. (2019). Interval-valued Pythagorean fuzzy Einstein hybrid weighted averaging aggregation operator and their application to group decision making. Complex \& Intelligent Systems, 5(1), 41-52. 
Rao, R. V., \& Rajesh, T. S. (2009). Software selection in manufacturing industries using a fuzzy multiple criteria decision making method, PROMETHEE. Intelligent Information Management, 1(03), 159.

Razavi Hajiagha, S. H., Hashemi, S. S., \& Zavadskas, E. K. (2013). A complex proportional assessment method for group decision making in an interval-valued intuitionistic fuzzy environment. Technological and Economic Development of Economy, 19(1), 22-37.

Ren, P., Xu, Z. and Gou, X. (2016). Pythagorean fuzzy TODIM approach to multi-criteria decision making, Applied Soft Computing 42:246-259.

Roy, J., Das, S., Kar, S., \& Pamučar, D. (2019). An Extension of the CODAS Approach Using Interval-Valued Intuitionistic Fuzzy Set for Sustainable Material Selection in Construction Projects with Incomplete Weight Information. Symmetry, 11(3), 393.

Sarkis, J. and Talluri, S. (2004). Evaluating and selecting e-com-merce software and communication systems for a supply chain. European Journal of Operational Research, Vol. 159, No. 2, pp. 318-329, 2004.

Talukdar, P., \& Dutta, P. (2019). Distance measures for cubic Pythagorean fuzzy sets and its applications to multicriteria decision making. Granular Computing, 1-18.

Tversky, A., Kahneman, D., 1992. Advances in prospect theory: Cumulative representation of uncertainty. Journal of Risk \& Uncertainty 5(4), 297-323

Victor, M., Upadhyay, N.: Selection of Software Testing Technique: A Multi Criteria Decision Making Approach. Springer Berlin Heidelberg, Berlin, Heidelberg, pp. 453- 462 (2011)

Wang, H., Qian, G., \& Feng, X. (2011). An intuitionistic fuzzy AHP based on synthesis of eigenvectors and its application. Information Technology Journal, 10(10), 1850-1866.

Wu, J., Huang, H. B., \& Cao, Q. W. (2013). Research on AHP with interval-valued intuitionistic fuzzy sets and its application in multi-criteria decision making problems. Applied Mathematical Modelling, 37(24), 9898-9906.

$\mathrm{Xu} \mathrm{Z}$, Zhang X. Hesitant fuzzy multi attribute decision making based on TOPSIS with incomplete weight information. Knowl Based Syst 2013; 52:53-64.

Xu, W., Shang, X., \& Wang, J. (2021). Multiple attribute group decision-making based on cubic linguistic Pythagorean fuzzy sets and power Hamy mean. Complex \& Intelligent Systems, 7(3), 1673-1693.

Yager, R.R. and Abbasov, A.M.(2013). Pythagorean membeship grades, complex numbers and decision making, Int J Intell Syst 28, 436-452.

Yazgan, H. R., Boran, S. and Goztepe, K. (2009). An ERP Software Selection Process with Using Artificial Neural Network Based on Analytic Network Process Approach. Expert Systems with Applications, 36 (5), pp. 9214-9222.

Zadeh, L. A. (1965). Fuzzy sets. Information and control, 8(3), 338-353.

Zanakis, S.H., Solomon, A., Wishart, N., S. Dublish, S. (1998). Multi-attribute decision making: A simulation comparison of selection methods European Journal of Operational Research, 107, pp. 507-529. 
Zhang, S., Li, X., Meng F. (2016). An approach to multi-criteria decision-making under interval-valued intuitionistic fuzzy values and interval fuzzy measures, Journal of Industrial and Production Engineering, 2016, Vol. 33, No. 4, 253-270.

Zhang, X., and Xu, Z. (2014). Extension of TOPSIS to multiple criteria decision making with Pythagorean fuzzy sets. International Journal of Intelligent Systems, 29(12), 1061-1078.

Zhou, F., \& Chen, T. Y. (2019). A Novel Distance Measure for Pythagorean Fuzzy Sets and its Applications to the Technique for Order Preference by Similarity to Ideal Solutions. International Journal of Computational Intelligence Systems, 12(2), 955-969. 